CASE STUDY

\title{
Reshaping System Culture at the North Carolina Community College System
}

September 10, 2015

Jessie Brown

Richard Spies

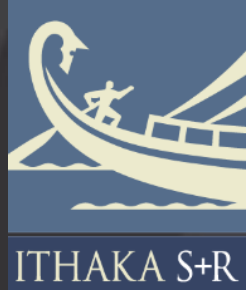




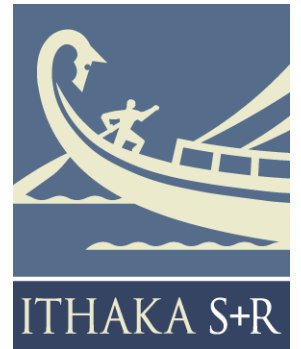

Ithaka $\mathrm{S}+\mathrm{R}$ is a strategic consulting and research service provided by ITHAKA, a not-for-profit organization dedicated to helping the academic community use digital technologies to preserve the scholarly record and to advance research and teaching in sustainable ways. Ithaka $\mathrm{S}+\mathrm{R}$ focuses on the transformation of scholarship and teaching in an online environment, with the goal of identifying the critical issues facing our community and acting as a catalyst for change. JSTOR, a research and learning platform, and Portico, a digital preservation service, are also part of ITHAKA.
Copyright 2015 ITHAKA. This work is licensed under a Creative Commons Attribution-NonCommercial 4.0 International License. To view a copy of the license, please see http://creativecommons.org/licenses/by-nc/4.0/.

ITHAKA is interested in disseminating this case study as widely as possible. Please contact us with any questions about using the case study: research@ithaka.org. 


\section{Introduction}

With 58 schools that enroll more than 800,00o students annually, the North Carolina Community College System (NCCCS) is the third largest system of higher education in the nation. ${ }^{1}$ In 2010, NCCCS embarked on SuccessNC, a strategic initiative focused on sharing best practices, developing performance-based student success metrics, and testing system-wide policies to improve student access and success across all NCCCS schools. The SuccessNC initiative states that its ultimate target is increasing "the percentage of students who transfer, complete credentials or remain continuously enrolled from a six-year baseline of 45 percent for the fall 2004 cohort to a six-year success rate of 59 percent for the fall 2014 cohort," therefore doubling the number of credential completers by $2020 .^{2}$

\section{SuccessNC's focus on access, excellence and success has permeated the priorities of both the System Office and institutions throughout the state}

Though still very much in progress, we were drawn to SuccessNC because it has shown early success in effecting a change in focus across a very large and complex system. Over the almost five years since Success NC's launch, hundreds of faculty, staff, and administrators have been involved in developing and implementing programs to improve student outcomes. SuccessNC's focus on access, excellence and success has permeated the priorities of both the System Office and institutions throughout the state, and stakeholders at various levels have collaborated across departments and campuses to meet SuccessNC goals. Outlining the process through which SuccessNC accomplished this culture change presents lessons for other systems engaged in large-scale reform.

How did this consensus develop and how did it empower faculty and administrators across the system to remake the culture of their institutions to focus on student success? Part of NCCCS' success can be attributed to a confluence of strong and determined leadership, a long tradition of innovation and change, important policy changes at the state level, and, of course, luck.

\footnotetext{
1 "Mission and History," North Carolina Community Colleges, http://www.nccommunitycolleges.edu/mission-history.

2 "About SuccessNC," SuccessNC, http://www.successnc.org/about-successnc.
} 


\section{NCCCS' continued success in developing consensus for system-wide initiatives is due in large part to well-defined roles that have been established for both the System Office and individual institutions in designing and implementing these reforms.}

However, NCCCS' continued success in developing consensus for system-wide initiatives is due in large part to the well-defined roles that have been established for both the System Office and individual institutions in designing and implementing these reforms. As NCCCS has implemented SuccessNC, the System Office has set priorities, delivered the framework for policies and investments, kept institutions accountable, and provided arenas for sharing, feedback, and inter-institutional support. Individual institutions have acted as collaborators in the design of initiatives and have fleshed out system-wide policies with a fair amount of local flexibility. The institutions that have been most successful in doing this have taken ownership of these policies, tailored them towards their students' needs, and integrated them with their own homegrown initiatives, strategic visions, and campus cultures.

In order to understand how these policies and processes were implemented and to what effect, we spent three days in North Carolina in June 2015, meeting with faculty, staff, and administrators at the NCCCS System Office and at two very different institutions within the system: Central Piedmont Community College (CPCC), a six-campus institution of nearly 70,000 students in Charlotte, and Nash Community College, a single-campus school of roughly 3,500 students in rural Rocky Mount. Though we were interested in student success initiatives and metrics in general, we focused during our visit on the Developmental Education Initiative (DEI), a system-wide redesign of North Carolina's Developmental Math, Reading, and English curricula. Because developmental education has historically been an area in which so many students struggle (in North Carolina and across the nation), the System Office identified DEI as an initiative with which to spearhead SuccessNC, and with which they could begin to reshape the system culture around student success.

Honing in on the DEI initiative allowed us to achieve a grounded understanding of the processes through which NCCCS achieved consensus across institutions and stakeholders, as well as some of the dynamics at work in the scaling of SuccessNC initiatives writ-large. The story of its design and implementation illustrates the balance 
struck between system-wide coordination and institutional autonomy in the design and implementation of critical system-wide initiatives. Refining this balance through the experience of implementing DEI has helped NCCCS develop the capacity to integrate system-wide initiatives into each institution's highest-priority planning, while engaging stakeholders from across the state in a long-term conversation about student success.

\section{Origins and Operations}

\section{Designing SuccessNC}

SuccessNC had its official launch in October 2009 with the announcement by NCCCS leadership that they would commit to a "system-wide strategic focus to increase student success, access, and program excellence." The idea of system-wide change was catalyzed by a proposal from President Scott Ralls at the 2009 retreat of the State Board of Community Colleges, but the initiative was given momentum and gained quick endorsement because it was grounded in long-standing concerns about higher education in North Carolina. In particular, the state suffered from a shortage of skilled workers for high-tech manufacturing jobs, and its growing banking, financial services, research and technology industries needed more college-educated employees. Additionally, after the financial crisis of 2008, state institutions of higher education struggled to meet the financial needs of students and applicants, putting pressure on broad-access institutions and community colleges to provide more students with a high quality education and meaningful credentials. While individual schools within NCCCS had launched a variety of initiatives to address these issues and promote student success, there existed few processes to learn about these innovations, share their successes, and scale them across the system. 3

SuccessNC began, then, with an effort by the System Office to learn about innovations at NCCCS institutions and to engage stakeholders across the system-from State Board members to campus faculty members-in a collective effort to improve student outcomes. The term "strategic focus" was deliberately chosen to reflect the difference between this effort-which focused on allocating existing resources and aligning efforts across the system and state (including with K-12 institutions and four-year colleges)and the more traditional "strategic plan" which normally aims to increase resources and expand an institution's mission.

A critical stage in the planning process was the 2010 "Listening Tour," in which NCCCS administrators visited the 58 campuses that make up NCCCS to identify best practices

${ }^{3}$ SuccessNC 2013 Final Report. 
and common barriers to student success. This process began in February 2010 and concluded with a meeting of the State Board the following October, during which the Board formally adopted the goals and plans for SuccessNC. At the same time, President Ralls appointed an "Innovative Ideas Committee," comprised of nearly two dozen college leaders from throughout the system, who identified which of the best practices surfaced during the Listening Tour could be scaled and which barriers could be removed by the System Office. Many of these barriers were bureaucratic issues that, once surfaced and assigned an owner, could be easily addressed. Solving as many of those small issues as quickly as possible was valuable in terms of building credibility for the collaborative approach that the System Office was taking, and, eventually, created space for stakeholders to focus on the more challenging barriers.

Between August 2010 and October 2011, the Innovative Ideas Committee pared more than 200 observed institutional innovations down to 15 initiatives that addressed widespread challenges and could be implemented or scaled across NCCCS. These initiatives included dual enrollment opportunities, financial aid simplification, minority male mentoring, articulation agreement revisions, reverse transfer credits, and the creation of data systems, performance measures, and performance funding policies directly related to student success. 4

In selecting these initiatives, the Innovative Ideas Committee was guided by three overarching goals, developed by the System Office's Strategic Planning initiative with input from State Board members, community college presidents, trustees, faculty members, staff, and system leaders. Succinctly stated, these goals were: "Improve Student Success," "Increase Student Access," and "Ensure Program Excellence." SuccessNC quantified these goals by setting the target, described above, to increase the portion of students "who transfer, complete credentials, or remain continuously enrolled from a six year baseline of 41 percent for the Fall of 2004 to a six-year success rate of 59 percent for the Fall 2014 cohort."

In addition to looking to these three goals for guidance, the Innovative Ideas Committee borrowed from the Bill and Melinda Gates Foundation's Completion by Design "Loss/Momentum Framework" that was already in use at several NCCCS schools, including CPCC. 5 The Gates "Student Success Framework" is organized around four stages in a student's community college experience: "Connection," or the time when a student develops an interest in college, "Entry," which spans first enrollment to the

${ }^{4}$ See the SuccessNC website for more information on each initiative, http://www.successnc.org.

${ }^{5}$ See "Our Approach," Completion by Design, http://www.completionbydesign.org/our-approach/key-resources-for-cbdframework. 
completion of gatekeeper courses, "Progress," the time a student enters a program of study to the time she completes 75 percent of required courses, and "Completion." Each of SuccessNC's initiatives fits into one of these phases.

\section{Each SuccessNC initiative is part of a larger strategy aimed at maintaining a student's momentum towards completion.}

Not only does the Student Success Framework bring a national perspective and credibility to the way the SuccessNC initiatives are planned and organized, but it also acts as a framework through which stakeholders can understand how each SuccessNC initiative is part of a larger strategy aimed at maintaining a student's momentum towards completion. For example, the DEI, discussed in more detail later in this report, exists within this framework as one of many initiatives intended to improve student success at the "Entry" phase. Employing this framework helped to align existing efforts in developmental education reform with separate and previously disconnected innovations around student advising, support, and financial aid simplification, and catalyzed cross-departmental and cross-campus efforts to improve students' early college experiences. In addition, the Student Success Framework shifts the focus from specific initiatives-some of which might not work at all institutions-to common goals and areas of focus, giving institutions some flexibility to improve student success rates in all four areas in ways that work best for their students, cultures, and access to resources.

The initiatives developed and framework designed from the SuccessNC Listening Tour and subsequent meetings remain the most visible aspects of SuccessNC. However, there was another byproduct of the SuccessNC planning process that has been foundational to NCCCS's ability to effect large-scale culture change. From this process, system leaders emerged with a clearer understanding of how to work across NCCCS to achieve statewide goals to meet student needs more effectively and efficiently In particular, when analyzing best practices and identifying SuccessNC initiatives to be scaled across the system, the Innovative Ideas committee articulated several broad themes that would guide SuccessNC's work. Quoting NCCCS language:

» The resources and capabilities of individual colleges are different. Colleges have different priorities that direct the allocation of resources, and this leads to different levels of capability and expertise at each college.

» Communications about innovations and interventions that lead to student success needs to be consistent, accurate, and credible.

» Scaling innovations to the system-wide level is challenging. 
» There are vast differences in the ways that colleges use technology to deliver instruction and to support student learning.

» Data should drive decision making. ${ }^{6}$

Since launching SuccessNC in 2009, these themes have deeply informed the way that the System Office goes about its work. For example, starting with the Listening Tours, the System Office has taken on the role of an aggregator and communicator for student success initiatives, publicizing institutional successes and providing venues for colleges to share their success stories and workshop challenges. Much of what the System Office sought to achieve in launching SuccessNC was the creation of a system through which innovations and best practices could be shared and institutions could collaborate. We heard of many instances of inter-institutional collaboration during our visits.

\section{The System Office has taken on the role of an aggregator and communicator for student success initiatives, publicizing institutional successes and providing venues for colleges to share their success stories and workshop challenges.}

Of course, the System Office does more than provide venues for communication about SuccessNC initiatives. In line with its commitment to data-driven decision-making, it also holds institutions accountable for achieving SuccessNC targets. In July 2013, the System Office reported on its first round of Performance Measures for Student Success. These measures are tied to individual SuccessNC initiatives and track institutional and system metrics on student progress on Basic Skills, GED diploma passing rates (for students in Adult Secondary Education), developmental student success in college-level courses, first year progression, completion rates for credential-seeking students, licensure and certification passing rates, and college transfer performance. For the 201314 academic school year, \$9 million of Performance Funding was distributed based on each college's relative rate of success on each measure, as well as the number of students

${ }^{6}$ SuccessNC 2013 Final Report, p 15. 
at that college who succeeded on each measure. For 2014-15, \$24 million was distributed.7

Finally, the notion that individual colleges differ in their resources, capabilities, and uses of technology has been a crucial part of the System Office's approach to implementing and managing SuccessNC initiatives. Indeed, it is difficult to imagine an effort aimed at aligning 58 schools across a state as diverse as North Carolina succeeding without an acknowledgement of the need for autonomy and flexibility. The processes through which DEI was designed and implemented - which balanced system-led coordination with institution-level collaboration and flexibility-illustrate this dynamic and the role it has played in facilitating broad-based consensus across the state.

\section{The Developmental Education Initiative}

Like many of SuccessNC's key initiatives, the Developmental Education Initiative was already under way when it was incorporated into the SuccessNC framework. In 2009, just months prior to the launch of SuccessNC, North Carolina joined five other states and fifteen schools to participate in a three-year, Gates and Lumina Foundation-funded initiative that aimed to reduce the need for developmental education, reduce the time it takes for students to complete a developmental sequence, and implement better tools for placing and assessing students. Facilitated by Jobs for the Future, the Community College Research Center and the North Carolina based non-profit MDC, the six states involved in DEI-Florida, Ohio, Texas, Connecticut, Virginia and North Carolinadeveloped a framework that targeted five key policy levers for state action: data and performance measurement; developmental education innovation and redesign: aligned expectations for K-12; assessment and placement; and finance. ${ }^{8}$

Because developmental education has historically posed such a significant stumbling block in students' early post-secondary experiences, and because it was already a statewide effort, System Office and college leaders selected DEI as one of SuccessNC's first major, system-wide efforts. Like other SuccessNC initiatives, DEI, despite its external origins, has been incorporated into SuccessNC's framework: its focus was initially guided by the 2010 Listening Tours, its design and implementation have been driven by the Innovative Ideas Committee's emerging themes, and its progress is evaluated by SuccessNC's Performance Measures. Along the way, DEI has been

\footnotetext{
${ }^{7}$ See "Performance Measures and Funding," SuccessNC, http://www.successnc.org/initiatives/performance-measuresfunding.

${ }^{8}$ See "The Developmental Education Initiative," Achieving the Dream, http://achievingthedream.org/resources/initiatives/developmental-education-initiative.
} 
incorporated with other "Entry" programs as part of a multi-initiative effort to help students maintain momentum early in their college experiences.

While SuccessNC has provided DEI with this basic framework, the actual, on-the-ground processes tested throughout the roll-out of DEI-such as multi-campus, crossdepartmental planning teams and task forces-have paved the way for broad consensus and coordination for other SuccessNC initiatives. In other words, while SuccessNC remains a high-level focus with long-term goals and a unifying framework, DEI has served as a vehicle through which to engage faculty, staff, administrators, and system leaders in concrete conversations about specific ways to boost and measure student success. Additionally, as one of SuccessNC's earliest system-wide reforms, DEI has catalyzed reforms in other areas such as advising and financial aid, while prompting system-wide logistical and technological coordination that will facilitate other large-scale changes.

\section{DEI has served as a vehicle through which to engage faculty, staff, administrators, and system leaders in concrete conversations about specific ways to boost and measure student success.}

A key turning point in engaging stakeholders from across NCCCS campuses in discussions about innovation and student success came during SuccessNC's listening tours and subsequent meetings, when institutional stakeholders were shown systemwide data on developmental math and asked to look at their own metrics. What was revealed was dire: system-wide, two-thirds of all students enrolled in developmental math, with low-income and minority students disproportionately affected. Of those who enrolled in the lowest level of the four-course developmental math sequence, only 8 percent ever completed a college-level math course.

While these statistics were shocking, campus faculty and administrators report that they were also catalyzing. When asked to examine and report their own institutional data on developmental classes, they confronted a similar picture. This process, they say, prompted them to take ownership of current issues and potential solutions while also initiating them into a shared effort to boost student success.

In addition to surfacing some troubling data, the Listening Tours provided a venue for faculty members to share with the System Office many common issues with 
developmental education. First, they argued that the placement tests that students took to place in or out of developmental education were poor diagnostic tools. These tests assessed test-taking skills more so than academic skills and, because students rarely prepared for the test, they frequently placed into remedial courses that they did not need to take. Second, the developmental courses were too long: those students who placed into the lowest developmental math course faced a four-semester sequence, and those students who placed into the lowest developmental reading and English courses faced a four-semester sequence in each area. This burden was compounded by high failure rates, which meant that a significant share of students had to retake entire semester longcourses, even if they had already demonstrated mastery of some of the concepts in the course. As a result, students could be held in developmental courses for semesters or even years at a time before being allowed to advance to college-level courses, and many became so frustrated with their lack of progress that they dropped out before completing their remedial coursework.

\section{College-based teams chose how to deliver the redesigned courses, how to incorporate technology and learning resources, how to use their instructional staff, and how to coordinate registration, financial aid, and advising to ensure that students succeeded.}

The process that followed for solving these problems was intensely collaborative. It balanced participation in the design process between the state and individual institutions in a way that allowed for college differences but still ensured a necessary level of standardization. First, a State Policy Team met in 2010 to establish policy principles to address NCCCS's specific problems with developmental math while meeting the standards of the state-wide DEI initiative. Because curricular redesign took primacy in the developmental education reform, faculty-led design task forces then developed the State Policy Team's curriculum-focused recommendations into explicit curricular changes, guidelines, and required competencies in developmental math, reading, and English. Finally, campus-based planning teams determined the details of the DEI implementation at the institutional level and were given flexibility to implement the changes in ways that fit best with the specific challenges they faced, resources they had available, and their institutional cultures. In particular, college-based teams chose how to deliver the redesigned courses, how to incorporate technology and learning resources, 
how to use their instructional staff, and how to coordinate registration, financial aid, and advising to ensure that students succeeded.

As the planning process was integrated from the state to the campus level, each of these planning teams enlisted broad-based participation from across the system. The DEI State Policy Team included President Ralls, representatives from state committees, the board, the System Office, and various areas at NCCCS colleges, including presidents, chief academic officers, developmental educators, and student support staff. Similarly, the curriculum task forces that fleshed out details of the policy team's design principles included faculty members from campuses across the state, each of whom was given six months of release time to draft guidelines for the redesigned courses. ${ }^{9}$ Campus planning and implementation teams have broken down departmental silos and incorporated administrators, faculty, advisors, financial aid and registration staff. With such broadbased participation, institutions have been able to ensure that the transition to the new developmental courses remains as smooth as possible for campus employees and students alike.

\section{Redesigning Developmental Math}

While developmental math, developmental English and developmental reading all posed several, similar challenges to NCCCS students, developmental math has historically had the lowest success rates system-wide. For this reason, developmental math was the first of the remedial areas that NCCCS addressed when carrying out DEI. The most welldeveloped of DEI reforms, the developmental math redesign (DMA) provides several examples of how the System Office and individual institutions navigated the design and implementation process to balance system-wide alignment with institutional flexibility.

To delve more deeply into some of the issues that students and institutions faced in developmental math and to devise solutions to these problems, the System Office assembled the DMA Task Force in 2009. Comprised of developmental faculty from schools across the state, the task force met regularly for several months, and used the DEI State Policy Team's design principles to flesh out a redesigned DMA curriculum that would allow students to progress more quickly through the DMA course sequence while ensuring a deeper level of mastery. The task force determined that the new developmental math curriculum would consist of eight modules, emphasize

\footnotetext{
${ }^{9}$ The DMA Task Force for Developmental Math consisted of faculty members from small and large colleges throughout the state, while the DRE Task Force for Developmental Reading and English only incorporated faculty from small and medium-sized colleges. Faculty members at CPCC, a large school that did not have a representative on this team, expressed some concerns about their exclusion from the design process.
} 
contextualized learning, and use a mastery-based pedagogical approach. Each module represented one semester hour credit and would be delivered in a four-week term. This way, if a student failed a module, he or she would only be set back by four weeks, rather than by an entire semester. Additionally, to address some of the placement issues caused by the diagnostic test, the DEI task force called for a system-wide implementation of a "multiple measures" placement policy so that a student who had completed certain math prerequisites and had earned a high school GPA above 2.6 could waive the placement test and place directly into college-level math. ${ }^{10}$

\section{Though technology is a major part of the DMA redesign at both schools, it is clear that these institutions have approached technology as a tool that supports quality instruction (and other services), rather than as a silver bullet sufficient for DMA's success.}

Though module competencies and learning objectives have remained consistent across campuses, institutions have autonomy to choose their delivery method (face to face, hybrid, or emporium model) and teaching resources for the new DMA curriculum. For example, the two institutions we visited both used hybrid, lab-assisted delivery methods for their DMA courses, but with significant differences they felt were important to their local circumstances. CPCC has implemented an Emporium model math lab in which lecture is replaced with interactive lab time using Pearson's MyMathLab and instructors act more as tutors than lecturers. ${ }^{11}$ Nash's "Math Tank" is similar to CPCC's Emporium lab, but the class format includes more lecture time and increased opportunities for small break out groups than does CPCC's model. Though technology is a major part of the DMA redesign at both schools, it is clear that these institutions have approached technology as a tool that supports quality instruction (and other services), rather than as a silver bullet sufficient for DMA's success.

\footnotetext{
${ }^{10}$ For more on concepts driving course redesign and implementation, see: "Developmental Math Modular Curriculum: Module Outlines and Notes," NCCCS (August 2011), http://ncmatyc.matyc.org/wpcontent/uploads/file/BetaVersionDevelopmental\%20Math\%20Modules\%20-\%20NCCCS\%5B1\%5D.pdf. For more on multiple measures, see the State Board approval of Placement Policies Memorandum (March 19, 2013), http://www.successnc.org/sites/default/files/inititiative-docs/SBCC\%20Placement\%20Policies.pdf.

${ }^{11}$ For more the Emporium model, developed by the National Center for Academic Transformation, see "How to Structure a Math Emporium: Advice from NCAT's Redesign Scholars," The National Center for Academic Transformation, http://www.thencat.org/R2R/AcadPrac/CM/MathEmpFAQ.htm.
} 
Just as schools enjoy some flexibility in how they deliver and teach the new modules, so too have institutions reorganized auxiliary areas, such as financial aid, registration, and student support services, in ways that best support their students, the details of their redesign, and their institutional circumstances. Nash, for example, has made holistic student support and an emphasis on community-a concept they call "Blue Love"-a central tenet of all of their student support efforts. In line with this approach, Nash has created a DMA registration system so that students remain with the same instructional team and student cohort for the entire duration of their developmental math sequence, regardless whether they progress at the same pace as the other students in their class. Technology in the Math Tank has been set up to support this, so that instructors can teach one subset of students, who might be in one module, while others, who may have advanced to the next module, work independently. This system creates a sense of community within a cohort, while ensuring that instructors remain accountable for students' success. Though implementing a system like this might be neither feasible nor desirable at a larger, more administratively complex school (like CPCC), the system has worked well with Nash's relatively small student body and distinctive campus culture.

The design process for Developmental Reading and English (DRE), which was implemented fully in fall 2014, was similar to DMA's. All institutions were guided by a bevy of system-wide design specifications when carrying out their redesigns, but they have interpreted and implemented these changes in varied ways. ${ }^{12} \mathrm{Nash}$, in particular, has taken ownership of the redesign, engaging in what they call a "redesign of the redesign" by breaking newly accelerated DRE classes (shortened from 16 weeks to 8 weeks) into three modules, so that students can pick up where they leave off if they fail to master an entire course. Nash also used the English redesign as an opportunity for faculty "enrichment" (Nash's term for faculty development) oriented around improving instruction and establishing processes for sharing and collaboration.

\footnotetext{
${ }^{12}$ The DRE task force redesigned the English and Reading curriculum (DRE) such that four semester-long courses (two in English, two in Reading) were replaced with eight-week long, three-credit hour "mini-mesters" that integrated English and Reading skills. Like DMA content, DRE course content now must be contextualized so that it covers topics relevant to career and college readiness (for DRE, this means that grammar can only be taught in context when presented during lecture). Courses are "technology enhanced," though institutions have a fair amount of room to interpret this principle, and student progression through the course is mastery-based. Provisions have been built into system-wide policies so that all DRE courses are graded as pass/retake, and so that students have opportunities to revise and resubmit each assignment within one week of the original due date. The redesigned courses were beta-tested in the spring of 2013, piloted the following fall and spring, and fully implemented in the fall of 2014. See "NCCCS Developmental Reading and English (DRE) Curriculum," (April 2013), http://www.successnc.org/sites/default/files/inititiativedocs/DRE\%20Document\%20Final\%20Version\%204.25.13.pdf 0.pdf.
} 
At both CPCC and Nash, DEI has become an integrated and crucial component of broader initiatives aimed at improving student success, especially early on in college. CPCC has leveraged work done and processes established during its work with Achieving the Dream and Completion by Design to successfully implement and track DEI, and to lead cross-institutional initiatives aimed at improving completion rates. ${ }^{13}$ Similarly, Nash has incorporated a stated shift in culture towards collaboration and student success initiated by its 2009 SACS accreditation to guide its implementation of DEI while structuring the initiative around its distinctive emphasis on community and holistic student support. ${ }^{14}$ In both cases, these institutions have not only integrated DEI into existing student success efforts, but have also used DEI-shared across NCCCS schoolsas a bridge to engage in a system-wide conversation about access, quality and completion. Both schools have emerged as leaders in SuccessNC efforts, and mentor other colleges through a statewide program called the "Performance Partnership." Faculty from Nash and CPCC have shared their DEI work at system-wide meetings, conferences and workshops. ${ }^{15}$

Now that all schools within the NCCCS have implemented DEI course redesigns and placement policies, the System Office's role has begun to evolve. Currently, the System Office is in the process of implementing the "Data Initiative," which will give stakeholders across the state access to a data tool that standardizes a larger set of institutional performance metrics and provides resources for data-driven decision making. Additionally, as institutions and the System Office continue to collect quantitative and qualitative data about DEI and other initiatives, the System Office will play a greater role in facilitating feedback, providing forums like the Performance Partnership to share best practices, and supporting faculty development initiatives as central to student success.

\footnotetext{
${ }^{13}$ See "Current Initiatives," Central Piedmont Community College, https://www.cpcc.edu/president/initiatives.

${ }^{14}$ Nash's Quality Enhancement Plan (QEP), a required component of its SACS reaccreditation, was "Fostering Opportunity, Cultivating Unparalleled Success: A FOCUSed First Year Experience." Nash faculty and administrators say that the process of developing the QEP was crucial in orienting the campus culture towards student success, and in establishing certain processes and systems (data collection, data-driven decision making, collaborative meetings, transparency) that enabled the successful roll-out of DEI. See "Fostering Opportunity, Cultivating Unparalleled Success: A FOCUSed First Year Experience" (September 2010), http://www.nashcc.edu/downloads/QEPFinal 070110.1616.pdf.

${ }^{15}$ The Performance Partnership is a college-driven, statewide program that facilitates collaboration among colleges and offers colleges with high success rates on state performance measures the opportunity to mentor other schools. See "Performance Partnership," SuccessNC, http://www.successnc.org/content/performance-partnership.
} 


\section{Evidence of Impact}

SuccessNC, while still very much a work in progress, has shown early indications of success and stands out as an example of culture change within a large and wellestablished system. Despite NCCCS' size and complexity, when it comes to the importance of student success, system leaders, administrators, faculty, and staff speak with as close to one voice as we have seen anywhere. Nearly everyone we interviewed mentioned-most without any prompting from us-the pre-SuccessNC statistic that only 8 percent of the students who started in the lowest level of developmental math ever successfully completed any college-level math course. This one piece of data presented during the Listening Tour provided a rallying point for stakeholders across the system and has become rooted in a shared narrative of reform.

Though only two years of Performance Measures data are available (many of these metrics were not captured before SuccessNC), a comparison of the 2013 and 2014 Performance Measures reports shows incremental progress towards system-wide goals. From the 2011-2012 to 2012-2013 academic years, the system-wide totals for Basic Skills student progress, the GED diploma passing rate, and first year progress each increased by a couple of percentage points (longer-term metrics, such as transfer and completion rates, have not yet been affected). Schools that have emerged as SuccessNC leaders, such as Davidson County Community College, Asheville-Buncombe Technical Community College (both of which piloted the new DMA courses), CPCC, and Nash have seen even greater improvements, especially in first year progression rates. ${ }^{16}$ Because these systemwide and institutional metrics will be crucial to track over time, NCCCS continues to invest in measuring, refining, and funding these specific standards.

Beyond these performance measures, which are defined and tracked by the System Office, individual institutions remain accountable for tracking data and evaluating the impact of student success initiatives on their students. Though graduation rates remain low-and an imperfect measure of student success at community colleges-CPCC increased three-year graduation rates from 8 percent to 12 percent from the Fall 2006 cohort to the Fall 2010 cohort. From the Fall 2007 cohort to the Fall 2014 cohort, fall to spring retention rates increased from 68 percent to 71 percent for all students, and from 81 percent to 87 percent for all full-time students. At Nash, first year progression rates

\footnotetext{
${ }^{16}$ For detailed metrics, see "2014 Performance Measures for Student Success Report," (July 2014), http://www.successnc.org/sites/default/files/inititiative-docs/2014 performance report 5-12-14.pdf. Increases from 20082009 to 2012-2013 are as follows: 60 percent to 72.1 percent at Asheville Buncombe, 69 percent to 71.7 percent at CPCC, 57 percent to 80 percent at Davidson, 59 percent to 61.4 percent at Nash.
} 
for credential seeking students increased from $47 \%$ in $2009-2010$ to $65 \%$ in $2010-2011$ after the implementation of FOCUS, its first-year student success program. Since then, first year progression rates have remained steady. ${ }^{17}$ Additionally, from the 2004 cohort to the 2008 cohort, the percentage of credential seeking students who retained, graduated or transferred within six years grew from $37 \%$ to $42 \% .{ }^{18}$

Of all schools within the system, CPCC has tracked the impact of DEI most rigorously, especially for developmental math courses. Data from CPCC shows that, after the implementation of multiple measures in 2014, the number of students who placed into college-level courses was 13 percentage points higher than in Fall of 2013. Moreover, those students who did place into college-level math through multiple measures policies have had higher success rates than the students who placed into the courses through placement tests. In fall 2014, 18 percent of all students who placed into a college-level math class did so because of their high school GPA. Of these students, 63.5 percent received an A, B, or C in their college-level math class, while only slightly more than 50 percent of those students who placed into the courses because of a diagnostic test received a passing grade. Additionally, as of the end of summer 2015, students who placed into college-level math or English because of their high school GPAs successfully completed these gateway courses within three terms at substantially higher rates than the students who placed in via diagnostic exams. While multiple measures students with high school GPAs in between 2.6 and 3.0 had lower success rates than those with GPAs above 3.0, early results from a Spring 2015 co-requisite course show that, with supplemental instruction, pass rates for the 2.6 to 3.0 students increased from 48 percent to 68 percent in MAT 171 (Pre-calculus). ${ }^{19}$

Though multiple measures now places fewer students into developmental math, since the curricular redesign, a greater portion of those students who do place into developmental math enroll and succeed in both DMA modules and college-level math courses. In the fall of 2011 and 2012, prior to the reform, almost 60 percent of CPCC students who placed into developmental math failed to enroll during their first term. By comparison, in fall of 2013, after the redesign, only 47 percent of those students who placed into developmental math avoided it during their first term. In fall of 2014, firstterm avoidance rates were down to 43 percent. ${ }^{20}$ This decrease in avoidance rates can

17 "FOCUS program, A FOCUS on Student Success," Nash Community College, http://www.nashcc.edu/index.php/community-topmenu-391/102-general-content/545-focus-program.

${ }^{18}$ All data provided by Nash Community College.

${ }^{19}$ Data provided by Brad Bostian, Director, First Year Experience, CPCC.

${ }^{20}$ Data provided by Brad Bostian. 
likely be explained, in part, by the new structure of the developmental math sequence: the four week modules seem less daunting to students than semester-long courses, and the prospect of retaking a four-week module if not successful is less discouraging than having to repeat an entire semester's worth of content.

Once students enroll in the new DMA modules, they have a greater likelihood of succeeding. In Fall 2012, when CPCC ran both pre-reform DMA courses and the new modular curriculum, 61 percent of pre-reform course takers earned a $\mathrm{C}$ or better, while 77 percent of module enrollees earned a $\mathrm{C}$ or better. ${ }^{21}$ Since the redesign, passing rates have been consistently and substantially higher in the new modules than they were in the old courses, even with many of the best-prepared students able to opt out of developmental math altogether in the new system. The number of students who earn a $\mathrm{C}$ or better college-level math has increased by $21 \%$, suggesting that developmental courses are now better preparing students for college-level work. ${ }^{22}$ Nash has seen similar results, especially in Developmental Reading and English from 2011-2012 to 2013-2014 (after the redesign), the percentage of DRE students who successfully completed a credit English course with a grade of $\mathrm{C}$ or better on their first attempt grew from $53 \%$ to $57 \% .{ }^{23}$

Finally, despite the upfront investment required, the developmental math redesign has proven to be cost-effective with a long-term return on investment. Initially, the accelerated format of the DMA modules and the implementation of multiple measures decreased developmental math full-time equivalent (FTE) enrollment by 49 percent at CPCC. However, this decrease was offset by a 37 percent increase in FTE enrollment in college-level courses, where students are more likely to succeed and persist. Instructional costs have remained steady, although IT costs and costs for increased services in counseling, financial aid, disability services and admissions have increased. CPCC anticipates that these costs will level out over time as the reforms become familiar to more students and employees. Overall, CPCC has experienced a high return on investment, with increased enrollment and higher success rates in college-level math. Both of these increases will ultimately put downward pressure on CPCC's costs per completion while increasing CPCC's eligibility for performance funding. ${ }^{24}$

\footnotetext{
${ }^{21}$ Data provided by Terri Manning, Vice President of Institutional Research, Central Piedmont Community College.

22 Increase from 2010-11 to 2013-14. Over this period of time, enrollment in college-level courses increased by $18 \%$. See Terri Manning, Bobbie Frye, Kathy Drumm,, Susan Burleson, Jennifer Allen, and Mike Sullivan, "Doing the Math on Developmental Reform: The Direct and Redirected Cost of Math Reform in North Carolina," (September 29, 2014), http://www.cpcc.edu/planning/studies-andreports/NC\%20CBD\%20final\%20cost\%20of\%20dev\%20math\%20white\%20paper\%2010.13.14.pdf.

${ }^{23}$ Data provided by Nash Community College.

${ }^{24}$ For a more sustained discussion of cost models for student success at the community college, see Thomas Bailey, Shanna Smith Jaggars, and David Jenkins, "Redesigning America's Community Colleges: A Clearer Path to Student Success" (Cambridge: Harvard University Press, 2015).
} 


\section{Success Factors}

Based on our conversations with President Ralls, members of his team at the System Office, and faculty and administrative leaders at the two campuses we visited, we have identified several factors that contributed to this distinctive level of system-wide change in culture and mindset. These include:

\section{An organizational structure and a governance system that balances system- wide consistency with institutional autonomy}

While each of the 58 colleges within NCCCS has its own governing board and campus president, each looks to the System Office for policy and strategic guidance. The System Office can also affect the allocation of resources to a certain degree, enabling system leaders to encourage certain kinds of initiatives and discourage others. Moreover, there is an unusual degree of system-wide guidance of the curriculum, extending even to common course numbering and common standards for most developmental and foundational courses and programs. This ability to set common standards for the curriculum was key to the success of the DEI and other curriculum redesign efforts that are a big part of SuccessNC. ${ }^{25}$

\section{Faculty members and department heads refer to redesign policies not as system mandates, but as guidelines within which they had-and continue to have-a significant degree of autonomy to test and implement what works best for their students.}

Despite this structure and the consistency it encourages, NCCCS has also been careful to allow schools a substantial amount of autonomy in their implementation of initiatives like DEI. This autonomy has encouraged institutions to take ownership of the initiative, and facilitated internal institutional processes that emphasize communication,

\footnotetext{
${ }^{25}$ These include the Curriculum Improvement Project, aimed at integrating energy efficiency skills into technical education pathways (see http://www.successnc.org/initiatives/code-green-super-cip-curriculum-improvement-project), and the Math Pathways Curriculum Improvement Project, which offers math pathways based on students education and career pathways (see http://www.successnc.org/initiatives/math-pathways-cip-curriculum-improvement-project-2012-2014).
} 
collaboration and transparency. In the most successful cases, faculty members and department heads refer to redesign policies not as system mandates, but as guidelines within which they had-and continue to have-a significant degree of autonomy to test and implement what works best for their students. The system's approach to the redesign, which incorporated input from faculty from colleges across the state and gave institutions flexibility to flesh out policies, has allowed for this local ownership without compromising a necessary level of standardization and accountability in DEI's design and system-wide implementation.

\section{A leadership team that has been focused and persistent about its goals and requirements}

In 2009, the leadership team took advantage of the combination of a new president (Scott Ralls), a major anniversary (50 years since the founding of NCCCS), data that demonstrated the need for significant improvement, and national research that provided direction for these improvements. Hit particularly hard by the recession, the state did not have the resources to support a broad-based expansion, so President Ralls coined the phrase "strategic focus" as a way of emphasizing the need to focus on a small number of critical goals and define a framework through which to develop and scale initiatives to meet these goals. This not-so-subtle shift in terminology from "strategic plan" to "strategic focus" was critical in terms of bringing existing resources-primarily the human resources represented by the faculty and staff on the 58 campuses-to bear on the goal of improving student success.

Additionally, system leadership has been particularly effective at building partnerships with campus presidents and academic officers, who, in turn, communicate and collaborate with faculty and staff on their campus to implement system-based initiatives. These partnerships have helped to sustain a solid base of support for SuccessNC, one that will likely sustain its momentum now that President Ralls-the initiative's primary champion-has transitioned out of the system as of Summer 2015.

\section{The strategic use of research and data}

From statistics presented during the Listening Tour to work done by individual task forces charged with implementing major initiatives, data have been used as a means of prompting inquiry, driving decisions, and evaluating initiatives-rather than as a form of surveillance or high stakes assessment. NCCCS continues to refine its methodologies for Performance Measures to make them more precise and meaningful and, from what we saw, each institution takes ownership of its performance-and ways to improve it-in much the same way each took initial ownership of developmental math success rates. Similarly, as individual initiatives have moved forward, research and data have been 
critical in guiding the work of the various task forces. For example, the Community College Research Center (CCRC) at Teacher's College partnered with NCCCS to conduct rigorous research on the predicted efficacy multiple measures at North Carolina community colleges. Additionally, the System Office is currently working with CCRC to track the DMA redesign's impact on costs and student outcomes. To date, CPCC's cost tracking work-which it has completed in partnership with the Gates Foundation and CCRC-has been very successful in justifying upfront investments in developmental math and allaying concerns about the impact of DEI on FTE funding from the state.

\section{Faculty and staff engagement in the effort}

From the campus-based Listening Tours, to the DEI State Policy Team that defined the DEI design principles, to the curriculum task forces and the institutional implementations of DEI, faculty and staff voices have been incorporated into SuccessNC and the DEI redesign at every step along the way. Turning to faculty and staff experts from a wide range of institutions-and treating them as design collaborators rather than subscribers to a new approach-infused the initiative with a level of credibility while incorporating grounded experiences into the redesign. By ensuring that this collaboration was cross-departmental, participants were able to coordinate around particular concerns related to registration, financial aid, and student support, so thatonce implemented-students could focus on academic rather than logistical concerns in their developmental education classes. This process of faculty and staff engagement has not only allowed for DEI to be implemented with broad-based support, but has also established collaborative design processes that have been used to develop other SuccessNC initiatives. ${ }^{26}$

\section{Remaining Challenges}

NCCCS' collaborative and coordinated approach offers important lessons for achieving system-wide reform. Of course, there were more than a few barriers to change, and NCCCS continues to face a number of obstacles as it moves forward with the implementation of SuccessNC.

One particular challenge lies in the funding structure for NCCCS schools (and community colleges nation-wide). Community colleges in North Carolina are funded per

\footnotetext{
${ }^{26}$ See, for example, the process by which NCCCS designed the Math Pathways Curriculum Improvement Project (CIP) which included several teams at the state, system, and institutional level. These included a broad-based Math CIP State Leadership Team; faculty-led liaison and steering committees with faculty members from community colleges across the state, and a Program Faculty Advisory Committee which represented non-mathematics staff. "Math Pathways CIP-20122014," SuccessNC, http://www.successnc.org/initiatives/math-pathways-cip-curriculum-improvement-project-2012-2014.
} 
FTE, so institutions can maximize their revenue by increasing enrollment, regardless whether students complete their degrees. While performance funding offers alternate financial incentives, and research indicates that FTEs lost in developmental courses are recaptured in college-level courses, some administrators were hesitant to implement DEI changes because they worried that it would cost their school state funding. As the system moves forward with scaling other initiatives that focus on completion rather than enrollment (a crucial component of the culture shift), leadership will have to be careful to distinguish between upfront and recurring expenses while reshaping the conversation about costs to one that focuses on cost per completion and long-term returns on investment.

Addressing some of the changes brought on by the implementation of the multiple measures placement policy presents another challenge, especially for faculty members in developmental and early college-level courses. Now that multiple-measures allows for higher-performing and better prepared students to place out of developmental courses, these classes are populated with larger concentrations of less -prepared students. Though helping these students succeed has always been a challenge, the implementation of multiple measures has surfaced that challenge in a particularly visible way. Additionally, because multiple measures has expanded the base of students who can enroll in college-level courses, faculty for these courses are finding that they have to teach and support students with a wider range of preparation. Both of these implications have added urgency to the need for faculty development, robust and integrated support services, and the establishment of college-ready policies in K-12 schools.

Though we have identified as a success factor the careful balance that NCCCS struck between clear and standard direction from the system on the one hand, and institutional flexibility on the other hand, maintaining this balance will present an on-going challenge. For curricular redesign initiatives in particular, including the Math Improvement Project and the Code Green Curriculum Improvement Project, there will be inevitable clashes between and among system-wide procedures, institutional approaches, and individual faculty needs. While we witnessed evidence that the System Office has created systems to help maintain this balance as DEI is refined, a crucial next step for NCCCS will be developing and managing faculty development programs and venues for feedback, collaborative problem-solving, and the sharing of best practices.

Looming on the horizon for SuccessNC is what President Scott Ralls calls the "next evolutionary phase" of the Data Initiative. Though data-driven inquiry and decision making have been a hallmark of all SuccessNC initiatives from inception, the System Office is now working on refining common metrics across the system, and developing a product through which stakeholders at institutions can easily access their own metrics, compare them to peer institutions, and access reports targeted towards strategic 
planning and impact evaluation. Once in place, NCCCS will have a much more robust toolset for keeping institutions accountable, enabling institutions to make data-informed decisions, and track progress towards system-wide, long term goals. However, the launching of the initiative will require a great deal of technical and logistical coordination amongst campuses (some of which has already been established through DEI) and will necessitate that stakeholders approach the process of data analysis with a renewed sense of rigor, inquisitiveness, and attention to institutional context.

President Scott Ralls' departure from the system in Summer 2015 presents a final challenge. While support for SuccessNC is broad and the prioritization it has placed on student success has permeated NCCCS's culture, there is no doubt that President Ralls' leadership has been crucial in catalyzing and sustaining these efforts. The State Board's June 2015 appointment of former Guildford Technical Community College Executive Vice President George Fouts, who has worked within NCCCS for 40 years and has been heavily involved in Completion by Design, indicates the system's long-term commitment to sustaining its focus on student success. ${ }^{27}$ However, like any transition in leadership, this one-which remains in progress with Fouts as an interim president-will test the momentum of NCCCS's collaborative approach and SuccessNC's broad-based support.

\section{Conclusion}

Though not the only system-wide community college effort aimed at improving student access, quality and success, NCCCS's SuccessNC stands out as an example for three reasons. First, it has been successful in coordinating institutions and stakeholders in a very large, complex and heterogeneous system. Second, it has successfully focused its resources and its efforts on the goal of student success and maintained that focus across institutions and over time. And, third, through this process of coordination, it has realized a noticeable culture shift that goes beyond any single leader or initiative. As NCCCS continues to scale initiatives and to make progress towards its 2020 goals, monitoring its accomplishments, as well as the evolution of systems and processes used for developing consensus, will provide valuable lessons for other systems looking to effect change.

SuccessNC has achieved its early successes with the implementation of DEI through an approach that positions the system office as a leader and coordinator, but incorporates institutional stakeholders into the design process and allows institutions to exercise

\footnotetext{
${ }^{27}$ See "State Board of Community Colleges Names Interim President," North Carolina Community College News (June 19, 2015), http://www.nccommunitycolleges.edu/news-center/news/state-board-community-colleges-names-interimpresident.
} 
considerable autonomy in their DEI implementations. Our visits to CPCC and Nash, where faculty spoke of DEI as their own-rather than as system mandates-made this especially clear. While other systems may function within different state contexts and under conditions that make system-wide coordination more feasible or more difficult, this balanced dynamic has been a crucial factor in NCCCS's success, and should be one that other institutions look to as a framework for developing their own approaches to reform.

\section{Appendix}

We conducted interviews with the following NCCCS faculty, staff, administrators, and System Office leaders from June 1 to June 4, 2015:

\section{System Office}

» Scott Ralls, NCCCS President

» Lisa Chapman, Senior VP \& Chief Academic Officer

» Wesley Beddard, AVP, Programs

» Kim Sepich, AVP, Student Services

» Cynthia Liston, Program Officer, John M. Belk Endowment

\section{Central Piedmont Community College}

» Richard Zollinger, Vice President for Learning and Workforce Development

» Edith McElroy, Dean, Levine Campus/Business, International and General Studies

» Laura Bazan, Division Director, English and Humanities

» Pat West, Marketing and Retailing Professor and CPCC Liaison to Achieving the Dream

» Karen Merriman, Dean of Professional Development and E-Learning

» Terina Lathe, Instructor of Sociology

» Terri Manning, Associate Vice President for Institutional Research and Assistant to the Executive Vice President

» Bruce Johnson, Associate Dean, STEM

» Rinav Mehta, Division Director, Mathematics

» Brad Bostian, Director, First Year Experience, English

\section{Nash Community College}

» Bill Carver, Nash Community College President

» Lisa Cooper, Humanities and Social Sciences (English) Department Chair

» Dina Pitt, Math Department Chair

» Jonathon Vester, Chief Information Officer

» Farley Phillips, Associate Dean of Institutional Effectiveness

"English and Math faculty members 